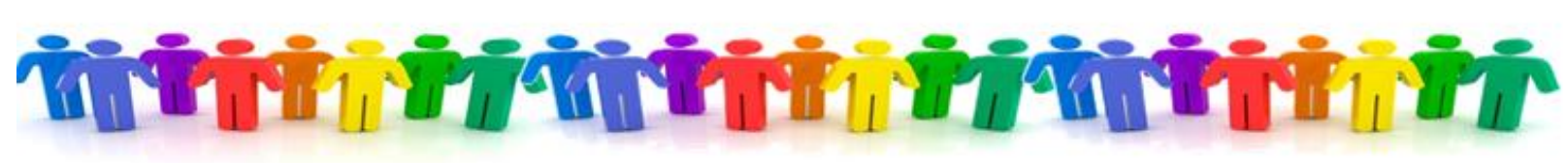

\title{
Older Women, Deeper Learning, and Greater Satisfaction at University: Age and Gender Predict University Students' Learning Approach and Degree Satisfaction
}

\author{
Mark Rubin, ${ }^{a}$ Jill Scevak, ${ }^{a}$ Erica Southgate, ${ }^{a}$ \\ Suzanne Macqueen, ${ }^{a}$ Paul Williams ${ }^{a}$ and Heather Douglas, ${ }^{a, b}$ \\ ${ }^{a}$ The University of Newcastle, Australia \\ ${ }^{b}$ Macquarie University
}

Citation: Rubin, M., Scevak, J., Southgate, E., Macqueen, S., Williams, P., \& Douglas, H. (2018). Older women, deeper learning, and greater satisfaction at university: Age and gender predict university students' learning approach and degree satisfaction. Journal of Diversity in Higher Education, 11, 82-96. doi: $10.1037 /$ dhe 0000042

\begin{abstract}
The present study explored the interactive effect of age and gender in predicting surface and deep learning approaches. It also investigated how these variables related to degree satisfaction. Participants were 983 undergraduate students at a large public Australian university. They completed a research survey either online or in hardcopy. Consistent with previous research, age was a positive predictor of both surface and deep learning. However, gender moderated this age effect in the case of deep learning: Age predicted deep learning more strongly among women and not among men. Furthermore, age positively predicted degree satisfaction among women but not among men, and deep learning mediated this moderation effect. Hence, older female students showed the greatest deep learning in the present sample, and this effect explained their greater satisfaction with their degree. The implications of these findings for pedagogical practices and institutional policy are considered.
\end{abstract}

Keywords: gender differences, deep learning, degree satisfaction, learning approach, surface learning.

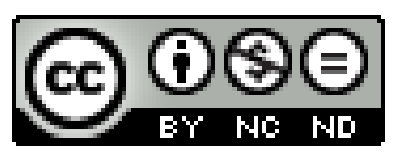

Copyright (C) The Authors. OPEN ACCESS: This material is published under the terms of the Creative Commons Attribution-NonCommercial-NoDerivatives 4.0 International licence (CC BY-NC-ND 4.0; https://creativecommons.org/licenses/by-

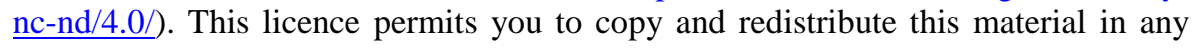
medium or format for noncommerical purposes without remixing, transforming, or building on the material provided that proper attribution to the authors is given.

This self-archived article is provided for non-commercial and scholarly purposes only.

This research was funded by a research grant from the National Centre for Student Equity in Higher Education Research Grants Program.

Correspondence concerning this article should be addressed to Mark Rubin at the School of Psychology, Behavioural Sciences Building, The University of Newcastle, Callaghan, NSW 2308, Australia. Tel: +61 (0)2 4921 6706. Fax: +61 (0)2 4921 6980. E-mail: Mark.Rubin@newcastle.edu.au Web: http://bit.ly/QgpV4O 
Researchers have distinguished between deep and surface learning approaches among students in higher education (e.g., Biggs, Kember, \& Leung, 2001; Marton, \& Säljö, 1976). Deep learning involves an active, independent, critical, and inquisitive form of learning. It often involves going beyond the set curriculum and relating the material to its wider context. It tends to be motivated by an intrinsic goal of wanting to learn for the sake of learning. In contrast, surface learning represents a more passive and instrumental approach. It may involve memorization and learning the material in a rote manner. The motivation behind surface learning is to learn just enough content in order to achieve some specific extrinsic goal, such as obtaining a pass grade (for an overview, see Cuthbert, 2005).

Although deep and surface learning are usually measured as individual difference variables, students may change their learning approach depending on the learning situation and goals that they encounter (Biggs \& Tang, 2007). Hence, these learning approaches are different from more fixed learning styles in that they are more flexible and adaptive to context (Cuthbert, 2005). It is also important to note that deep and surface learning may be conceived as being relatively orthogonal constructs. So, for example, students may adopt both deep and surface learning approaches depending on the material that they learn.

The concepts of surface and deep learning have been formalised since the 1970s (Marton \& Säljö, 1976), and they have infiltrated the language of everyday teachers. However, relatively little research has considered demographic differences in these learning approaches. In the present research, we considered age and gender differences in deep and surface learning among university students. It is important to consider these sorts of demographic differences in the context of higher education because the student population is becoming more and more diverse in its demographic constitution (e.g., Benson, Heagney, Hewitt, Crosling, \& Devos, 2013). In particular, the proportion of older students at university study has increased over the last twenty years, and the literature suggests that this new cohort has brought new challenges with it (e.g., Mallman \& Lee, 2014; Stone \& O'Shea, 2013).

The present research also investigated how age and gender differences in learning approach influence students' satisfaction with their degree. Hence, the main aim of the current research was to provide a better understanding of age and gender differences in university students' learning and satisfaction at university. We begin by reviewing literature that has considered age differences in learning approach before turning to gender differences in learning approach. We then considering the potential for an interaction between age and gender in determining learning approach and, potentially, degree satisfaction.

\section{Age Differences in Learning Approach}

Researchers in this area have distinguished between "older" or "mature-aged" students and "young" or "traditional-aged" students. However, there is no clear consensus about the aged-based cut-off point for these categories. Some researchers have considered 23 years to be a key threshold (e.g., Andreou, Vlachos, and Andreou, 2006; Sadler-Smith \& Tsang, 1998). However, this is a relatively arbitrary cut-off point, and other researchers have chosen different cut-off points. In the present research, we considered age as a continuous variable rather than a categorical variable, and so we use the terms "younger" and "older" as relative terms in order to describe students who are younger or older than other students rather than being younger or older than any absolute specified age threshold.

Previous research has found that older students have less of a surface learning approach and more of a deep learning approach than younger students (e.g., Aaron \& Skakun, 1999; Fragoso 
et al., 2013; Harper \& Kember, 1986; Hilliard, 1995; Justice \& Dornan, 2001; Richardson, 1994, 1995, 2013; Salamonson et al., 2013; Zeegers, 2001; for a recent review of a 31 supportive studies, see Richardson, 2013). Several theoretical explanations have been put forward for this age difference (for a review, see Richardson, 1994). The theoretical explanation that guides the present research was originally put forward by Harper and Kember (1986). These researchers proposed that older students engage in less surface learning and more deep learning because they are motivated more by intrinsic goals than by extrinsic, career-oriented goals (see also Richardson, 2013). In other words, younger students adopt a more instrumental approach to their education, seeing it as a means to obtain a job rather than to educate themselves, and this results in more of a surface learning approach and less of a deep learning approach. Consistent with this explanation, older students tend to be more intrinsically motivated than younger students (Bye, Pushkar, \& Conway, 2007), younger students tend to be more extrinsically motivated than older students (e.g., Simpson, Sturges, Woods, \& Altman, 2005; for a review, see Richardson, 1994), and extrinsic motivation predicts surface learning and intrinsic motivation predicts deep learning (Moneta \& Spada, 2009; Prat-Sala \& Redford, 2010).

\section{Gender Differences in Learning Approach}

If differences in intrinsic and extrinsic motivation underlie age differences in learning approach, then other demographic groups that differ in intrinsic and extrinsic motivation should also differ in learning approach. Gender groups are relevant here because men and women have been found to differ in their intrinsic and extrinsic learning motivation (Severiens \& Ten Dam, 1994).

In their meta-analysis of gender differences in learning styles, Severiens and Ten Dam (1994) found that men scored higher than women in their extrinsic motivation and lower than women in their intrinsic motivation. The researchers concluded that men are more interested in earning qualifications, and women are more interested in "learning for learning's sake" (p. 498). Consistent with this conclusion, research has shown that women are more focused than men on intrinsic career rewards (e.g., Powell \& Maneiro, 1993; Russo, Kelly, \& Deacon, 1991; Simpson, 2000; Sturges, 1999).

However, despite the evidence of gender differences in intrinsic and extrinsic motivation, the evidence for concomitant gender differences in learning approach is equivocal. Consistent with expectations, some studies have found that female students are more likely than male students to engage in more deep and/or less surface learning (Heijne-Penninga, Kuks, Hofman, \& CohenSchotanus, 2010; Salamonson et al., 2013; Tarabashkina \& Lietz, 2011). However, other studies have found no significant gender difference in learning approach (e.g., Heikkilä \& Lonka, 2006; May, Chung, Elliott, \& Fisher, 2012; Richardson, 1993, 2013; Wilson, Smart, \& Watson, 1996; Zeegers, 2001). Furthermore, some studies have found opposite effects in which female students are less likely than male students engage in more deep and/or less surface learning (e.g., SadlerSmith, 1996; for a meta-analytic review, see Severiens \& Ten Dam, 1994; for reviews of further evidence, see Richardson, 2013; Richardson \& King, 1991; Wilson et al., 1996).

One reason for this mixed evidence may be that gender differences in learning approach have relatively small effect sizes and are therefore difficult to detect, especially using small sample sizes (Wilson et al., 1996). The present study overcame this problem by using a relatively large sample $(N=983)$. 


\section{An Interaction Between Age and Gender in Predicting Learning Approach?}

The present research also explored the possibility of an interaction between age and gender in determining learning approach. The theoretical rationale for predicting this interaction effect relates to the career-orientations of younger and older men and women.

Women tend to be more heterogeneous and complex than men in their career-orientations because, as they grow older, they are more likely to switch between a focus on their career and a focus on their family life (Gerber, Wittekind, Grote, \& Staffelbach, 2009; Hakim, 2000). In particular, younger female students are likely to be more career-oriented and less family-oriented than older female students (e.g., O’Shea, 2014; Reay, 2003; Thacker \& Novak, 1991). In contrast, men of all ages tend to have "more linear, traditional career patterns" (Gerber et al., 2009, p. 306).

Based on this career-orientation perspective, we assumed that age is a significantly stronger predictor of learning approach among women than among men because there is greater variability in career-orientation between younger and older women than there is between younger and older men. In particular, older female students should have less of a surface learning approach and more of a deep learning approach than younger female students because older female students are less concerned about their career. In contrast, younger and older male students should have similar learning approaches because they have a similar focus on their careers.

\section{Prior Research Investigating a Gender by Age Interaction}

To our knowledge, only two previous studies have investigated the interactive effects of age and gender on student learning approach. Andreou et al. (2006) aimed to understand how students' gender, age, degree type, and handedness affected approaches to studying. They sampled 452 students from a medium-sized university in central Greece and measured several learning approaches using a 30-item version of Entwistle and Tait's (1995) Revised Approaches to Studying Inventory. They found a significant interaction between age, gender, and degree program in predicting deep learning. Both older men and women had a deeper learning approach than younger men and women, but this effect varied according to degree program (applied sciences vs humanities).

Sadler-Smith and Tsang (1998) conducted a study to compare the cross-cultural validity of the Revised Approaches to Studying Inventory in Hong Kong and the UK and to investigate gender and age differences in learning approaches. They sampled second-year business undergraduates from Hong Kong $(N=183)$ and the UK $(N=225$; Sadler-Smith, 1996). They found a significant interaction between age and gender in the Hong Kong sample but failed to replicate this effect in the UK sample (Sadler-Smith, 1996). Contrary to our predictions, the Hong Kong interaction showed that older male students had more of a deep learning approach than younger male students, and that older female students had less of a deep learning approach than younger female students.

A strength of this past work is that has tested the cross-cultural validity of the concepts of deep and surface learning in Greece, the UK, and Hong Kong and found that deep and surface learning emerged as clear factors. This evidence converges with other work that has found configural invariance in other measures of learning approaches (Leung, Ginns, \& Kember, 2008). Hence, the meaning of self-report items that assess deep and surface learning appears to be relatively constant across the cultures and educational systems that have been studied.

However, there are two key weakness with this prior research. First, Andreou et al. (2006) and Sadler-Smith and Tsang (1998) provided conflicting evidence regarding the interaction between age and gender in predicting learning approach. Andreou et al. found that older male and female students had a deeper learning approach than younger male and female students, but that 
this effect varied according to degree program. Sadler-Smith and Tsang found that older male students had a deeper learning approach than younger male students, and that older female students had a less deep learning approach than younger female students, but this interaction only occurred in a Hong Kong sample and was not replicated in a UK sample. Hence, further research is required in this area in order to provide clearer conclusions about the interactive effect of age and gender on learning approach.

Second, a methodological issue limits confidence in these studies' findings and may even account for the inconsistencies in their results. Both studies treated age as a categorical variable rather than a continuous variable, splitting their samples into younger students of less than 23 years and older students of greater than 23 years (for the same concern, see Richardson, 2013). As Maxwell and Delaney (1993) explained, there are two problems with this artificial dichotomization approach. First, it can "dramatically lower power to detect true interactions" (Maxwell \& Delaney, 1993, p. 187). In other words, it can increase the rate of false negative (Type II) errors. Second, it "can create the illusion of an interaction where none exists" (p. 187). In other words, it can also increase the rate of false positive (Type I) errors. Notably, both problems persist for variables such as age that may be skewed and have nonlinear relationships with outcome variables (DeCoster, Iselin, \& Gallucci, 2009; Maxwell \& Delany, 1993, p. 182). We avoided both of these problems in the present research by treating age as a continuous variable. This approach increased the power and sensitivity of our statistical tests.

\section{Degree Satisfaction}

The present research also investigated age and gender differences in degree satisfaction and how these relate to age and gender differences in learning approach. Degree satisfaction (or student satisfaction) is becoming more and more important for at least two reasons. First, it predicts student persistence (for a review, see Schertzer \& Schertzer, 2004), and so it provides an early warning indicator of potential student attrition. Second, it is a key factor in determining the ranking of universities against one another, and university rankings are commonly used in marketing and funding exercises.

We predicted that a deep learning approach would be positively associated with degree satisfaction because deep learning is an intrinsically-rewarding learning approach, and students who are intrinsically motivated are likely to be more interested in their studies and experience positive affect (Bye et al., 2007). Consistent with this prediction, the few studies that have investigated the relationship between learning approach and degree satisfaction have found that deep learning is associated with greater satisfaction with teaching and learning environments and methods (Gurpinar, Kulac, Tetik, Akdogan, \& Mamakli, 2013; Parpala, Lindblom-Ylänne, Komulainen, Litmanen, \& Hirsto, 2010; for a brief review, see Parpala et al., 2010, p. 270).

To our knowledge, however, no prior research has considered how age and gender differences in learning approach relate to degree satisfaction. It is important to investigate this issue because age and gender differences in degree satisfaction (e.g., de Jager \& Gbadamosi, 2013; Thacker \& Novak, 1991) may be related to age and gender differences in learning approach. Indeed, given that deep learning is positively associated with degree satisfaction, age and gender differences in deep learning may help to explain (i.e., mediate) age and gender differences in degree satisfaction.

\section{Summary of the Research Predictions Tested in the Current Study}

Based on a substantial body of previous research (e.g., for a review, see Richardson, 2013), 
we predicted that older students would be more likely than younger students to report more deep learning and less surface learning. Given that learning approach is underpinned by motivation (Harper \& Kember, 1986; Richardson, 2013), and women have more intrinsic motivation and less extrinsic motivation than men (e.g., Severiens \& Ten Dam, 1994), we also predicted that female students would be more likely than male students to report more deep learning and less surface learning.

Given that women tend to be more heterogeneous in their career-orientations than men (Gerber et al., 2009; Hakim, 2000), we predicted an interaction between age and gender such that age differences in learning approach would be larger among female students than among male students. Finally, given that deep learning predicts greater satisfaction with teaching and learning environments and methods (e.g., Gurpinar et al., 2013; Parpala et al., 2010), we predicted an interaction between age and gender on degree satisfaction such that age differences in degree satisfaction would be larger among female students than among male students. We also investigated whether age and gender differences in deep learning mediate age and gender differences in degree satisfaction.

\section{Participants}

\section{Method}

Participants were 983 undergraduate students at a large public Australian university. Participants comprised a convenience sample from five broad degree types: allied health (podiatry, 12.51\%; nutrition and dietetics, 2.24\%; occupational therapy, 10.27\%), the sciences (science, 12.11\%; environmental science and management, 8.95\%; medical radiation science, .31\%), engineering (mechanical engineering, 3.97\%; construction management, 1.53\%), business and commerce (10.78\%), and medicine (13.43\%). The remaining $9.77 \%$ of students did not indicate their degree program. The estimated total enrolment number for the degree programs from which the sample was drawn was 6,790. Hence, the study's response rate was $14.48 \%$.

The sample included 552 women $(56.15 \%), 428$ men $(43.54 \%)$, and 3 people who did not indicate their gender $(0.31 \%)$. These gender proportions were relatively balanced and representative of the university's population $(54.85 \%$ women; $45.15 \%$ men). The sample contained 507 first-years students $(51.57 \%), 224$ second-year students $(22.79 \%)$, and $2353^{\text {rd }}, 4^{\text {th }}$, or $5^{\text {th }}$ year students $(23.91 \%)$, as well as 17 students who did not respond to this study level item $(1.73 \%)$.

Participants ranged in age from 17 to 70 years with a mean age of 23.06 years $(S D=6.50)$. Five students did not indicate their age. Based on institutional data, the mean age of the university population was 25.08 years. Male participants ranged in age from 18 to 66 years with a mean age of $23.01(S D=6.25)$. Female participants ranged in age from 17 to 70 years with a mean age of $23.10(S D=6.68)$. There was no significant gender difference in students' age, $t(974)=.11, p=$ 916. Participants from allied health degrees were significantly older $(M=24.58, S D=7.81)$ than participants in the other degree types apart from medicine $(p s \leq .006)$, and participants in medicine degrees were significantly older $(M=23.92, S D=4.89)$ than participants in the commerce and engineering degrees $(p s \leq .042)$. To address these differences, we investigated whether degree type moderated our results in our analyses.

There were 13 participants who self-identified as Aboriginal (1.32\%), 1 who self-identified as Torres Strait Islander $(0.10 \%)$, and 102 who self-identified as having a non-English speaking background (10.38\%).

In response to an item that asked about their carer responsibilities (e.g., for children, 
parents, relatives/friends), $11.50 \%$ of participants indicated that they had carer responsibilities "often" or "constantly," 84.84\% indicated that they had these responsibilities "rarely" or "sometimes," and $3.66 \%$ did not respond to this item.

In response to an item that asked whether they were the first in their family to attend university, $33.37 \%$ indicated that they were first-in-family and $65.21 \%$ indicated that they were not, $0.92 \%$ indicated that they did not know, and $0.51 \%$ did not respond.

Finally, participants reported that they worked for pay for an average of 12.01 hours per week $(S D=11.32)$.

\section{Procedure and Measures}

The survey was advertised to students via announcements in online course systems, emails, and visits by the researchers to lectures and tutorials. Participation was on a voluntary basis. Participants completed a 15-minute survey either online or in hardcopy.

We measured deep and surface learning using the revised two-factor Study Process Questionnaire (Biggs et al., 2001). This is a popular measure of learning approach, and it has been used in several previous studies to investigate age differences in learning approach (for a review, see Richardson, 2013). The scale contains 10 items that assess surface learning and 10 items that assess deep learning. An example of a deep learning item is "I work hard at my studies because I find the material interesting." An example of a surface learning item is "my aim is to pass the course while doing as little work as possible." The scale's two-factor structure has been confirmed using both exploratory and confirmatory factor analyses (Justicia, Pichardo, Cano, Berbén, \& De la Fuente, 2008), and it shows configural invariance across different degree types, levels of study (undergraduate, postgraduate), and cultures (Australia, Hong Kong; Leung, Ginns, \& Kember, 2008). Participants responded to the scale items using a 5-point scale that was anchored never or only rarely true of me (1) and always or almost always true of me (5). Both subscales' scores had good internal reliability (Cronbach alphas: deep learning $\alpha=.81$; surface learning $\alpha=.78$ ). Consequently, mean values were computed for each subscale.

We measured students' satisfaction with their degree using a purpose-built 4-item measure that referred to degree application to goals, organisation, course integration, and feedback. The items were as follows: "I am able to apply my learning in this degree to my wider goals;" "overall, the courses in my degree are well-organised;" "I can see how the courses in my degree are connected to develop my learning;" and "in this degree, I received feedback that is helpful to my learning." These items were based on items that the institution used to assess students' degree satisfaction. Participants responded to these items using a 4-point scale that was anchored strongly disagree (1) and strongly agree (4). In a principal axis factor analysis, a scree plot indicated a single factor solution. In addition, a parallel analysis on 100 random data sets each comprising of 4 variables and 983 participants showed that only the first factor in the real data set had an eigenvalue (2.24) that was larger than the four factors indicated in the simulated data sets (1.07, $1.02,0.98, \& 0.93)$. Consequently, we specified the extraction of a single factor, which accounted for $55.96 \%$ of the variance. All four items loaded highly on this single factor $(\geq .54)$, and the scale's scores had good internal reliability $(\alpha=.73)$. Again, mean values were computed for this measure.

The survey contained a number of other measures. A full copy of the research survey is available from the corresponding author on request. 


\section{Data Analysis}

With regards to missing data, if a participant responded to $75 \%$ or more of the items used to create a scale (e.g., 8 or more items of a 10-item scale or 3 or more items of a four-item scale), then their data were included in the analyses, and their missing data was replaced with the sample mean for each item. If a participant did not respond to $25 \%$ or more of the items in a scale, then all of their data for that scale were removed from analyses. The cut-off of $25 \%$ was based on empirical and pragmatic reasons: Empirically, it has been shown that mean substitution is an appropriate method of handling missing data as long as the number of affected items within a scale represent no more than $20 \%$ of the total scale items (Downey \& King, 1998). However, our shortest measure was the four-item measure of degree satisfaction, and so, for pragmatic reasons, we increased this limit to $25 \%$ in order to allow mean substitution if 1 out of 4 items had missing data (i.e., $25 \%$ missing data) but not if 2 or more of 4 items had missing data (i.e., $\geq 50 \%$ missing data). We should note that missing data were minimal in our data set $(<6 \%)$, and that prior research has demonstrated that mean substitution is an appropriate method of handling missing data as long as the missing data represents less than $20 \%$ of the data set (Downey \& King, 1998).

We used Hayes' (2013) PROCESS software to investigate the independent and interactive effects of age and gender on learning approach and degree satisfaction. PROCESS provides a powerful method of investigating interaction effects between continuous and categorical predictor variables, and so it was ideally suited to test our predicted interaction effects between students' age (continuous variable) and gender (categorical variable).

Following our theoretical framework, we investigated age as a predictor variable, gender as a moderator variable, and deep learning, surface learning, and degree satisfaction as outcome variables. Age was substantially positively skewed (skewness $=3.01$ ). In order to produce a more normal distribution, we transformed this variable by computing its log 10 values (skewness = 1.90). We coded gender as 1 for male students and 2 for female students. Age and gender were both centered prior to computing interaction terms.

We also used PROCESS to investigate a potential mediated moderation effect in which deep learning explained (mediated) the interactive effects of age and gender on degree satisfaction.

\section{Results}

Table 1 provides the means, standard deviations, sample sizes, and a zero-order correlation matrix for age, surface learning, deep learning, and degree satisfaction.

Table 1

Descriptive Statistics and Zero Order Correlation Coefficients

\begin{tabular}{|c|c|c|c|c|c|c|}
\hline Measure & $M$ & $S D$ & $n$ & 1 & 2 & 3 \\
\hline 1. Age & 23.06 & 6.50 & 978 & - & & \\
\hline 2. Surface learning & 2.41 & 0.65 & 923 & $-.23 * *$ & - & \\
\hline 3. Deep learning & 2.77 & 0.64 & 934 & $.18 * *$ & $-.23 * *$ & - \\
\hline 4. Degree satisfaction & 2.99 & 0.50 & 929 & .05 & $-.20 * *$ & $.32 * *$ \\
\hline
\end{tabular}

\section{The Effects of Age and Gender on Learning Approach}

We considered predictors of surface learning first and predictors of deep learning second. Table 2 shows the results of these analyses. 
Table 2

Gender, Age, and their Interaction as Predictors of Learning Approach and Degree Satisfaction

\begin{tabular}{lcccccc}
\hline & \multicolumn{5}{c}{ Outcome variable } \\
\cline { 2 - 7 } Predictor & \multicolumn{2}{c}{ Surface learning } & \multicolumn{2}{c}{ Deep learning } & \multicolumn{2}{c}{ Degree satisfaction } \\
\cline { 2 - 7 } variable & $B(S E)$ & $95 \% \mathrm{CI}$ & $B(S E)$ & $95 \% \mathrm{CI}$ & $B(S E)$ & $95 \% \mathrm{CI}$ \\
\hline Gender & $-0.15^{* *}(0.04)$ & {$[-0.23,-0.07]$} & $0.03(0.04)$ & {$[-0.05,0.11]$} & $0.05(0.33)$ & {$[-0.02,0.11]$} \\
Age & $-1.54^{* *}(0.22)$ & {$[-1.96,-1.12]$} & $1.17 * *(0.21)$ & {$[0.75,1.59]$} & $0.25(0.17)$ & {$[-0.09,0.58]$} \\
Gender x Age & $-0.17(0.44)$ & {$[-1.02,0.69]$} & $0.97 *(0.43)$ & {$[0.12,1.82]$} & $0.77 *(0.35)$ & {$[0.08,1.45]$} \\
$R^{2}$ & 0.07 & & 0.04 & & 0.01 & \\
$n$ & 916 & & 927 & & 922 & \\
\hline
\end{tabular}

Note. $B=$ Unstandardised beta. $S E=$ Standard error. $\mathrm{CI}=$ Confidence interval. Age was log 10 transformed for these analyses to reduce skew. The pattern of significant and nonsignificant results remained identical when the analyses were repeated without replacing any missing data and when the age variable was not log 10 transformed. Visual inspection of scattergrams confirmed that the pattern of results was not driven by outliers. Degree program and year of study did not moderate the gender by age interactions on learning approaches or degree satisfaction ( $p s \geq .166$ ). Hence, these results were independent of degree program and year of study.

$* p<.05, * * p<.001$

Consistent with expectations, gender was a significant negative predictor of surface learning, indicating that female students had less of a surface learning approach than male students. Age was also a significant negative predictor of surface learning, indicating that, consistent with previous research, older students had less of a surface learning approach than younger students. However, contrary to expectations, there was no significant interaction between age and gender in predicting surface learning.

Gender did not have a significant overall effect on deep learning. However, consistent with predictions, age was a significant positive predictor of deep learning, indicating that older students had more of a deep learning approach than younger students. This effect was qualified by a significant interaction between age and gender. To investigate this interaction, we compared the conditional effects of age on deep learning among male and female students separately. As expected, age was a stronger predictor of deep learning among female students than among male students. Among female students, age positively predicted deep learning, indicating that older women were deeper learners than younger women, $B=1.60, S E=0.28, t(1)=5.76, p<.001,95 \%$ CI $(1.05,2.14)$. In contrast, among male students the positive relation between age and deep learning was much weaker and only approaching the conventional level of significance, $B=0.62$, $S E=0.33, t(1)=1.87, p=.06,95 \% \mathrm{CI}(-0.03,1.28)$. This interaction effect is illustrated in Figure 1 .

Note that there has been some concern in the literature that the size of individual differences in learning approaches may be insufficiently large to warrant concern from educators (Richardson, 2013, p. 76; Wilson et al., 1996, p. 61). In the present research, the overall effect of age on deep learning was relatively small in size (Pearson $r=.18$ ). However, when the effect was considered for women per se, it was a medium-sized effect (Pearson $r=.25$ ). This is a relatively impressive effect size given that the median effect size in psychology is only $r=.16$ (Cafri, Kromrey, \& Brannick, 2010), and even effects as small as .03 can have important real-world implications (McCartney \& Rosenthal, 2000; Rosenthal, 1994). 
Figure 1

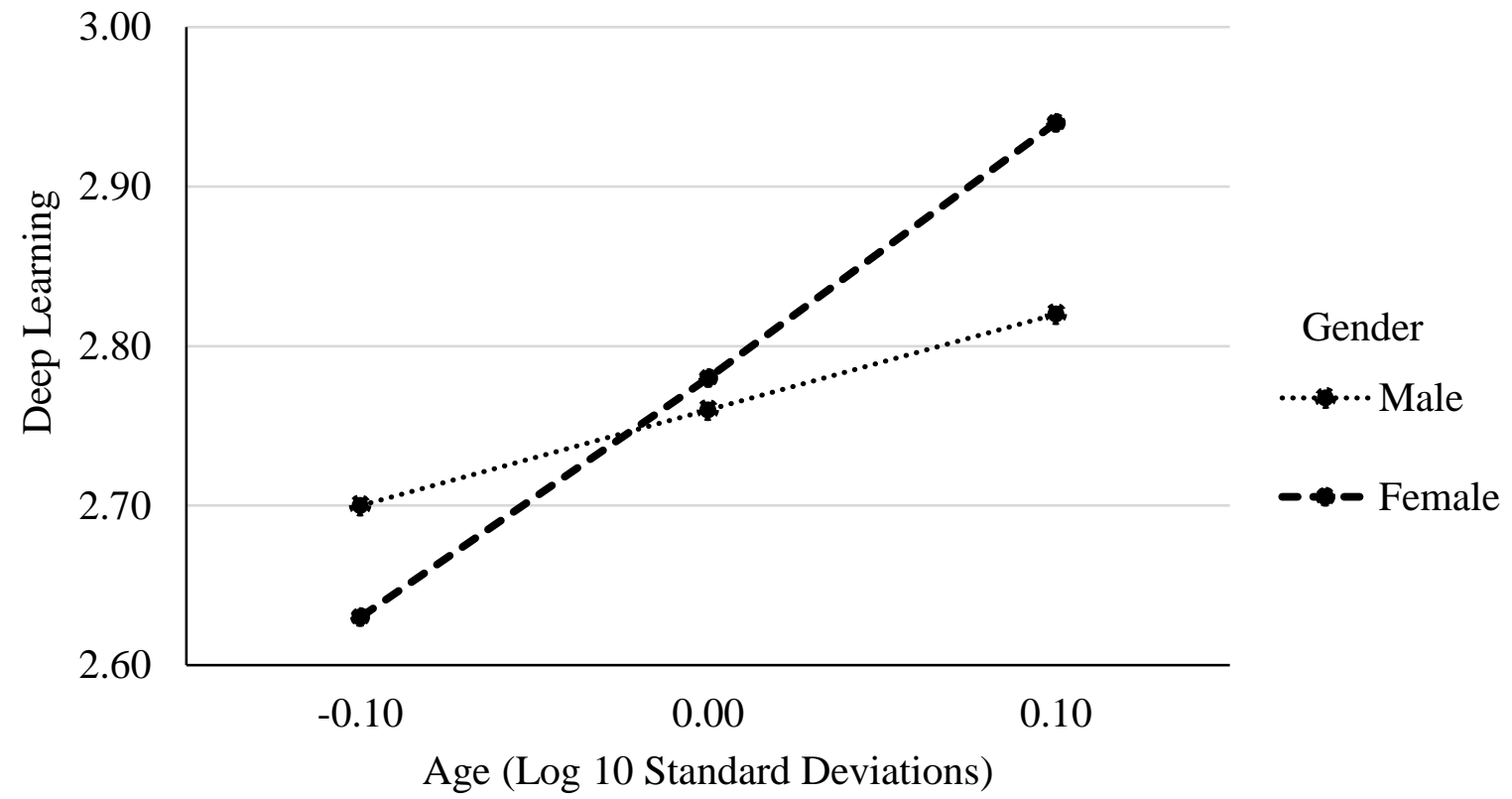

Figure 1. The interactive effect of age and gender on deep learning.

\section{The Effects of Age and Gender on Degree Satisfaction}

We also considered the effects of age and gender on students' satisfaction with their degree. As can be seen in Table 2, neither age nor gender showed significant overall effects on degree satisfaction. However, there was a significant interaction between these two variables in predicting degree satisfaction. We compared the effects of age on degree satisfaction among male and female students separately and obtained a pattern of results that paralleled that for deep learning: Age was a significant predictor of degree satisfaction among female students but not among male students. Among female students, age positively predicted degree satisfaction, $B=0.58, S E=$ $0.22, t(1)=2.61, p=.009,95 \% \mathrm{CI}(0.14,1.01)$. Among male students, the relation between age and degree satisfaction was not significant, $B=-0.19, S E=0.27, t(1)=-0.70, p=.483,95 \%$ CI ($0.72,0.34)$. This interaction effect is illustrated in Figure 2.

\section{Mediation Analysis}

Our initial results showed that age was a significant positive predictor of both deep learning and degree satisfaction, but that both of these effects were stronger among female students than among male students. Given this pattern of results, it is possible that older women's deeper learning helps to explain their greater degree satisfaction. To test this possibility, we conducted a mediated moderation analysis in which we investigated the degree to which deep learning explained (mediated) the interactive effects of age and gender on degree satisfaction.

We used Hayes' (2013) PROCESS Model 8 to test this mediated moderation model. This model uses a path analytical framework and bootstrapping to provide powerful estimates of direct and indirect effects. We entered age and gender as predictor variables, deep learning as the mediator variable, and degree satisfaction as the outcome variable. In order to provide a powerful estimate of the reliability of the associated indirect effect (i.e., the total effect minus the direct effect), we used 5,000 bootstrapping iterations to obtain bias-corrected and accelerated bootstrap 95\% confidence intervals. This analysis showed that the indirect effect of the gender by age interaction on degree satisfaction via deep learning was significant, $B=0.26$, bootstrapped $S E=$ 
$0.10,95 \% \mathrm{CI}(0.07,0.48)$. In other words, deep learning mediated the gender by age interaction effect on degree satisfaction.

Figure 2

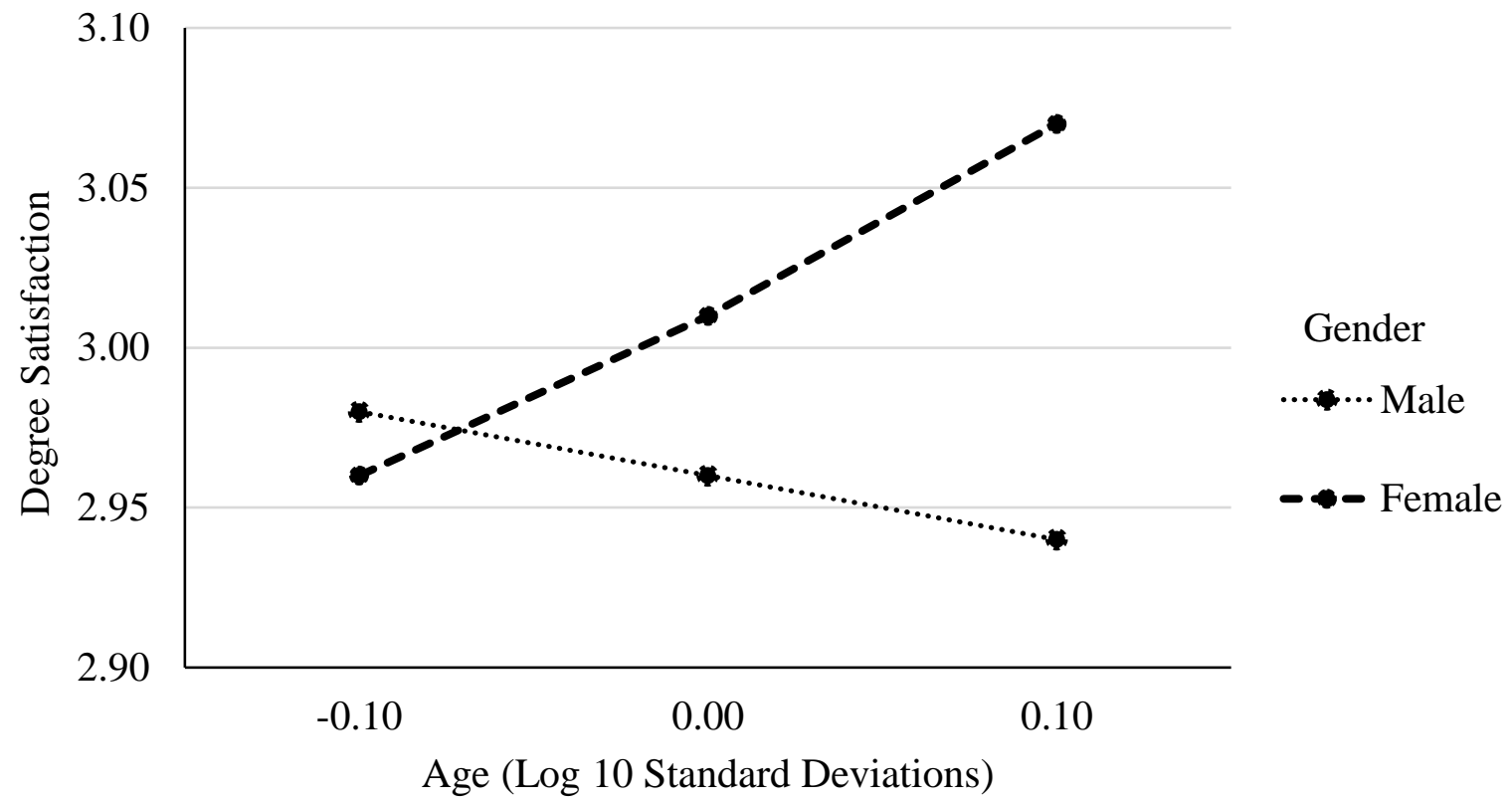

Figure 2. The interactive effect of age and gender on degree satisfaction.

Note that the interpretation of mediated moderation analyses is controversial. In particular, Hayes (2013) argues that the interaction term used in this analysis is "meaningless" in the sense that it does not relate to any specific measure (p. 387). We would argue that this interaction term does have a significant meaning in the context of intersectional variables such as age and gender because it indicates the extent to which students are older women or younger men. Nonetheless, we considered a second, less controversial way of interpreting the above results as a moderated mediation effect (Hayes, 2013). In this case, we investigated the conditional mediating effect of deep learning at each level of gender. Consistent with expectations, deep learning was a significant mediator of the relation between age and degree satisfaction among female students, $B=0.43$, bootstrapped $S E=0.08,95 \% \mathrm{CI}(0.25,0.57)$, but not among male students, $B=0.13$, bootstrapped $S E=0.08,95 \%$ CI $(-0.02,0.30)$. Among female students, the total effect of age on degree satisfaction was significant, $B=0.57$, bootstrapped $S E=0.22,95 \% \mathrm{CI}(0.14,0.99)$, the direct effect controlling for deep learning was nonsignificant, $B=0.19$, bootstrapped $S E=0.21,95 \%$ CI (-0.23, $0.61)$, and the indirect effect was significant, $B=0.38$, bootstrapped $S E=0.08,95 \%$ CI $(0.23$, 0.57). This pattern of results indicated that differences in deep learning fully mediated age differences in degree satisfaction among female students.

It should also be appreciated that, in the context of our cross-sectional design, it is unclear whether deep learning causes degree satisfaction, degree satisfaction causes deep learning, or whether there is a bidirectional causal relationship between these two variables. To explore this issue, we conducted a further mediated moderation analysis in which we reversed the putative causal ordering of deep learning and degree satisfaction in our model. In other words, we investigated whether degree satisfaction mediated the interaction between age and gender on deep learning. This analysis showed that the indirect effect of the gender by age interaction on deep learning via degree satisfaction was significant, $B=0.29$, bootstrapped $S E=0.14,95 \%$ CI $(0.04$, 
0.59). Hence, it is possible that older women's differences in degree satisfaction influenced the subsequent extent of their deep learning.

\section{Summary of Findings}

\section{Discussion}

This study investigated the independent and interactive effects of undergraduate students' age and gender on their learning approach and degree satisfaction. Consistent with previous work, older students had less of a surface learning approach and more of a deep learning approach than younger students (for a recent review of similar findings, see Richardson, 2013). However, a major contribution of the present work is to show that this age difference effect was qualified by gender in the case of deep learning: Age was a stronger predictor of deep learning among women than among men. It is quite possible that this interaction effect was not tested in many previous studies. Future studies should test for not only age differences in deep learning, but also age and gender interaction effects.

The present empirical results correspond with qualitative work that has documented the reasons given by younger and older women for entering higher education (McCune, Hounsell, Christie, Cree, \& Tett, 2010; Thacker \& Novak, 1991). For example, McCune et al. (2010) found that older students reported intrinsic motives for their education. As one of their older female respondents explained, "I'm not doing this because I want to change my job. I'm not doing this because I think it's going to get me any more money, I'm doing it because I want to learn" ( $p$. 696). Similarly, Reay (2003) found that "mature women students were much more likely to evoke a love of learning as their reason for further study" (p. 304). Again, an older female respondent from this study explained that "I'm not doing it for vocational reasons. I'm doing it for me" (p. 304). The present research extends this qualitative work by demonstrating that older female students are empirically distinct from younger female students and men of all ages in terms of their deep learning approach.

Notably, age and gender only interacted to predict deep learning and not surface learning in the present research. In the case of surface learning, age and gender showed only independent effects: Older students and women had less of a surface learning approach than younger students and men respectively. The reasons for the discrepancy between the results for deep and surface learning are unclear and warrant further investigation.

A second major contribution of the present research is that it extends previous work that has shown that deep learning is associated with satisfaction with teaching and learning environments and methods (e.g., Gurpinar et al., 2013; Parpala et al., 2010). In the current study, we found that age differences in deep learning mediated age differences in degree satisfaction but only among women and not among men. Older women were more satisfied with their degrees than younger women, and a corresponding age difference in deep learning explained this age difference in degree satisfaction. Hence, the present research provides a clearer understanding of the different reasons that specific types of students have for valuing their degree experience.

\section{Comparison with Previous Research}

Previous empirical research in this area has yielded inconsistent findings (Andreou et al., 2006; Sadler-Smith \& Tsang, 1998). We believe that these inconsistent findings may be attributed to three methodological problems, which the present study overcomes.

First, the present research used a sample that was twice the size $(N=983)$ of the largest sample that has been used to test the age-gender interaction in previous research (Andreou et al., 
2006, $N=452$; Sadler-Smith \& Tsang, 1998, $N=182$ ). This point is important given that both age differences and gender differences in learning approach are relatively small effects (Richardson, 2013; Wilson et al., 1996). The use of a larger sample in the present research meant that the results were less likely to be the result of either false positive (Type I) or false negative (Type II) errors.

Second, the present research did not artificially dichotomize age in its analyses (e.g., $<23$ years $\&>23$ years) but instead treated age as a continuous variable. Again, this approach increased the power of the statistical tests and limited the chance of Type I and II errors (DeCoster et al., 2009; Maxwell \& Delaney, 1993).

Third, the present research sampled students from a diverse range of degree programs and confirmed that degree program did not moderate the key effects (cf. Andreou et al., 2006).

\section{Limitations and Directions for Future Research}

It is important to acknowledge a number of limitations of the present research. First, the research sampled students from a single Australian institution, and it obtained a relatively low response rate $(14.48 \%)$. Consequently, the research findings may be limited to this specific sample, the institution, and/or its local sociocultural context. Future research should attempt to replicate the present results using larger samples from different universities and different countries. For example, recent research has found that Asian students are more likely than Australian students to adopt a deep learning approach (Bowden, Abhayawansa, \& Manzin, 2015). Hence, a fruitful angle for future research may be to examine age and gender differences in learning approach among Australian and Asian students.

Second, our measures of deep and surface learning did not tap actual cognitive processing or behavioural derivatives of this processing but rather self-reported learning approaches. Prior research has found some evidence of cognitive process criterion validity for the type of self-report measure that we used (for a review, see Dinsmore \& Alexander, 2012). However, it would be information for future research to relate age and gender differences in learning approaches to actual differences in cognitions and behaviours.

Third, although our measure of age provided a relatively objective, continuous assessment of students" age, it did not assess students' social identities as being "young" or "old" or "matureaged" in the context of the university population. This more subjective and categorical approach to age may provide a useful complement to the more objective continuous measure in future research.

Fourth, the present research did not confirm that older women prefer a deep learning approach because they are more intrinsically motivated and less career-oriented. As discussed in the Introduction section, there is already a substantial theoretical and empirical basis for these assumptions (Gerber et al., 2009; Hakim, 2000; Harper \& Kember, 1986; Moneta \& Spada, 2009; O'Shea, 2014; Reay, 2003; Powell \& Maneiro, 1993; Prat-Sala \& Redford, 2010; Russo et al., 1991; Severiens \& Ten Dam, 1994; Simpson, 2000; Simpson et al., 2005; Sturges, 1999; Thacker \& Novak, 1991). Nonetheless, future research should test the full proposed model in a single study by including measures of intrinsic and extrinsic motivation as well as career-orientation. In this context, it would be informative to assess whether older women are returning to higher education or whether their education was delayed due to financial constraints.

Finally, the cross-sectional correlational research design that was employed in the present research limits the potential for causal conclusions. Given the relatively intransigent nature of age and gender, differences in students' age and gender are more likely to cause differences in learning 
approach and degree satisfaction than vice versa. However, the causal direction between learning approach and degree satisfaction is much less clear. Although it is possible that differences in deep learning caused differences in degree satisfaction, it is also possible that differences in degree satisfaction caused differences in deep learning, or that both variables influenced one another in a bidirectional manner. The results of our mediation analyses do not discount any of these three possibilities. Future research should use a longitudinal research design in order to distinguish between these possibilities.

\section{Implications}

The present research provides the first reliable evidence that age and gender interact to predict deep learning and degree satisfaction such that age positively predicts deep learning and degree satisfaction among women more than among men. These results highlight the intersectional nature of university students' age and gender when considering individual differences in deep learning and degree satisfaction. A key implication is that teachers in higher education should not think about their students in terms of either their age or their gender when considering their learning approach but in terms of both their age and their gender.

The present research results also challenge the conventional wisdom that "the "ideal learner', from an institutional view, is young, well-resourced and not bound by conflicting family obligations" (Mallman \& Lee, 2014, p. 3). If "ideal learners" are expected to be active, independent, critical, and inquisitive students who go beyond the set curriculum, then older women should be regarded as more ideal than younger women and men of all ages.

The research also has a potential pedagogical implication in relation to peer mentoring. Student peer mentoring has been shown to be an effective way of changing learning approaches. For example, first-year undergraduate accountants who were mentored by third-year students about the process of learning did not show the decrease in deep learning that non-mentored students showed as they progressed (Fox, Stevenson, Connelly, Duff, \& Dunlop, 2010). Based on the present research, older women may be particularly influential student mentors because they are able to convey a particularly deep learning approach to other students.

The present research also has an important institutional policy implication. Many universities are under substantial funding pressures to improve their rankings with respect to degree satisfaction. The present research shows that older women report greater satisfaction with their university degrees than younger women and men of all ages. Hence, one method that universities can use to improve their degree satisfaction rankings is to encourage a greater proportion of enrolments from older women.

In conclusion, the present research throws a spotlight on older women as a special group when considering deep learning and degree satisfaction, at least at the Australian university that was investigated in the present research. Future research should focus more on this underinvestigated group of students in higher education.

\section{References}

Aaron, S., \& Skakun, E. (1999). Correlation of students' characteristics with their learning styles as they begin medical school. Academic Medicine, 74, 260-262. doi: 10.1097/00001888199903000-00016

Andreou, E., Vlachos, F., \& Andreou, G. (2006). Approaches to studying among Greek university students: The impact of gender, age, academic discipline and handedness. Educational Research, 48, 301-311. doi: 10.1080/00131880600992363 
Benson, R., Heagney, M., Hewitt, L., Crosling, G., \& Devos, A. (2013). Managing and supporting student diversity in higher education: A casebook. Oxford, UK: Chandos.

Biggs, J., Kember, D., \& Leung, D. Y. (2001). The revised two-factor study process questionnaire: R-SPQ-2F. British Journal of Educational Psychology, 71, 133-149. doi: 10.1348/000709901158433

Biggs, J. B., \& Tang, C. (2007). Teaching for quality learning at university. Berkshire: Open University Press/McGraw-Hill Education.

Bowden, M. P., Abhayawansa, S., \& Manzin, G. (2015). A multiple cross-cultural comparison of approaches to learning. Compare: A Journal of Comparative and International Education, 45, 272-294. doi: 10.1080/03057925.2013.841465

Bye, D., Pushkar, D., \& Conway, M. (2007). Motivation, interest, and positive affect in traditional and nontraditional undergraduate students. Adult Education Quarterly, 57, 141-158. doi: $10.1177 / 0741713606294235$

Cafri, G., Kromrey, J. D., \& Brannick, M. T. (2010). A meta-meta-analysis: Empirical review of statistical power, type I error rates, effect sizes, and model selection of meta-analyses published in psychology. Multivariate Behavioral Research, 45, 239-270. doi: $10.1080 / 00273171003680187$

Cuthbert, P. F. (2005). The student learning process: Learning styles or learning approaches?. Teaching in Higher Education, 10, 235-249. doi: 10.1080/1356251042000337972

de Jager, J., \& Gbadamosi, G. (2013). Predicting students' satisfaction through service quality in higher education. The International Journal of Management Education, 11, 107-118. doi: 10.1016/j.ijme.2013.09.001

DeCoster, J., Iselin, A. M. R., \& Gallucci, M. (2009). A conceptual and empirical examination of justifications for dichotomization. Psychological Methods, 14, 349-366. doi: 10.1037/a0016956

Dinsmore, D. L., \& Alexander, P. A. (2012). A critical discussion of deep and surface processing: What it means, how it is measured, the role of context, and model specification. Educational Psychology Review, 24, 499-567. doi: 10.1007/s10648-012-9198-7

Downey, R. G., \& King, C. V. (1998). Missing data in Likert ratings: A comparison of replacement methods. The Journal of General Psychology, 125, 175-191. doi: 10.1080/00221309809595542

Entwistle, N. J. \& Tait, H. (1995). Revised approaches to studying inventory. University of Edinburgh, Centre for Research on Learning and Instruction, Edinburgh.

Fox, A., Stevenson, L., Connelly, P., Duff, A., \& Dunlop, A. (2010). Peer-mentoring undergraduate accounting students: The influence on approaches to learning and academic performance. Active Learning in Higher Education, 11, 145-156. doi: $10.1177 / 1469787410365650$

Fragoso, A., Goncalves, T., Ribeiro, C. M., Monteiro, R., Quintas, H., Bago, J., ... \& Santos, L. (2013). The transition of mature students to higher education: Challenging traditional concepts? Studies in the Education of Adults, 45, 67-81.

Gerber, M., Wittekind, A., Grote, G., \& Staffelbach, B. (2009). Exploring types of career orientation: A latent class analysis approach. Journal of Vocational Behavior, 75, 303-318. doi: $10.1016 /$ j.jvb.2009.04.003

Gurpinar, E., Kulac, E., Tetik, C., Akdogan, I., \& Mamakli, S. (2013). Do learning approaches of medical students affect their satisfaction with problem-based learning? Advances in Physiology Education, 37, 85-88. doi: 10.1152/advan.00119.2012 
Hakim, C. (2000). Work lifestyle choices in the 21 st century. Oxford, UK: Oxford University Press. Harper, G., \& Kember, D. (1986). Approaches to study of distance education students. British Journal of Educational Technology, 17, 212-222. doi: 10.1111/j.14678535.1986.tb00510.x

Hayes, A. F. (2013). An introduction to mediation, moderation, and conditional process analysis: A regression-based approach. New York, NY: Guilford Press.

Heijne-Penninga, M., Kuks, J., Hofman, W. H., \& Cohen-Schotanus, J. (2010). Assessment: Influences of deep learning, need for cognition and preparation time on open-and closedbook test performance. Medical Education, 44, 884-891. doi: 10.1111/j.13652923.2010.03732.x

Heikkilä, A., \& Lonka, K. (2006). Studying in higher education: Students' approaches to learning, self-regulation, and cognitive strategies. Studies in Higher Education, 31, 99-117. doi: 10.1080/03075070500392433

Hilliard, R. I. (1995). How do medical students learn: Medical student learning styles and factors that affect these learning styles. Teaching and Learning in Medicine: An International Journal, 7, 201-210. doi: 10.1080/10401339509539745

Justicia, F., Pichardo, M. C., Cano, F., Berbén, A. B. G., \& De la Fuente, J. (2008). The revised two-factor study process questionnaire (R-SPQ-2F): Exploratory and confirmatory factor analyses at item level. European Journal of Psychology of Education, 23, 355-372. doi: 10.1007/BF03173004

Justice, E., \& Dornan, T. (2001). Metacognitive differences between traditional-age and nontraditional-age college students. Adult Education Quarterly, 51, 236-249. doi: $10.1177 / 074171360105100305$

Leung, D. Y., Ginns, P., \& Kember, D. (2008). Examining the cultural specificity of approaches to learning in universities in Hong Kong and Sydney. Journal of Cross-Cultural Psychology, 39, 251-266. doi: 10.1177/0022022107313905

Mallman, M., \& Lee, H. (2014). Stigmatised learners: Mature-age students negotiating university culture. British Journal of Sociology of Education, 1-18. doi: 10.1080/01425692.2014.973017

Marton, F., \& Säljö, R. (1976). On qualitative differences in learning: I-Outcome and process. British Journal of Educational Psychology, 46, 4-11. doi: 10.1111/j.20448279.1976.tb02980.x

Maxwell, S. E., \& Delaney, H. D. (1993). Bivariate median splits and spurious statistical significance. Psychological Bulletin, 113, 181-190. doi: 10.1037/0033-2909.113.1.181

May, W., Chung, E. K., Elliott, D., \& Fisher, D. (2012). The relationship between medical students' learning approaches and performance on a summative high-stakes clinical performance examination. Medical Teacher, 34, e236-e241. doi: $10.3109 / 0142159 x .2012 .652995$

McCartney, K., \& Rosenthal, R. (2000). Effect size, practical importance, and social policy for children. Child Development, 71, 173-180. doi: 10.1111/1467-8624.00131

McCune, V., Hounsell, J., Christie, H., Cree, V. E., \& Tett, L. (2010). Mature and younger students' reasons for making the transition from further education into higher education. Teaching in Higher Education, 15, 691-702. doi: 10.1080/13562517.2010.507303

Miller, C. D., Finley, J., \& McKinley, D. L. (1990). Learning approaches and motives: Male and female differences and implications for learning assistance programs. Journal of College Student Development, 31, 147-154. 
Moneta, G. B., \& Spada, M. M. (2009). Coping as a mediator of the relationships between trait intrinsic and extrinsic motivation and approaches to studying during academic exam preparation. Personality and Individual Differences, 46, 664-669. doi: 10.1016/j.paid.2009.01.012

O'Shea, S. (2014). Transitions and turning points: Exploring how first-in-family female students story their transition to university and student identity formation. International Journal of Qualitative Studies in Education, 27, 135-158. doi: 10.1080/09518398.2013.771226

Parpala, A., Lindblom-Ylänne, S., Komulainen, E., Litmanen, T., \& Hirsto, L. (2010). Students' approaches to learning and their experiences of the teaching-learning environment in different disciplines. British Journal of Educational Psychology, 80, 269-282. doi: 10.1348/000709909X476946

Powell, G., \& Maneiro, L. (1993). Getting ahead-In career and in life. In G. Powell (Ed.), Women and men in management ( $2^{\text {nd }}$ ed., pp. 84-96). Newbury Park, CA: Sage.

Prat-Sala, M., \& Redford, P. (2010). The interplay between motivation, self-efficacy, and approaches to studying. British Journal of Educational Psychology, 80, 283-305. doi: 10.1348/000709909X480563

Reay, D. (2003). A risky business? Mature working-class women students and access to higher education. Gender and Education, 15, 301-317. doi: 10.1080/09540250303860

Richardson, J. T. E. (1993). Gender differences in responses to the Approaches to Studying Inventory. Studies in Higher Education, 18, 3-13. doi: 10.1080/03075079312331382418

Richardson, J. T. E. (1994). Mature students in higher education: I. A literature survey on approaches to studying. Studies in Higher Education, 19, 309-325. doi: 10.1080/03075079412331381900

Richardson, J. T. E. (1995). Mature students in higher education: II. An investigation of approaches to studying and academic performance. Studies in Higher Education, 20, 5-17. doi: 10.1080/03075079512331381760

Richardson, J. T. E. (2013). Approaches to studying across the adult life span: Evidence from distance education. Learning and Individual differences, 26, 74-80. doi: 10.1016/j.lindif.2013.04.012

Richardson, J. T. E, \& King, E. (1991). Gender differences in the experience of higher education: Quantitative and qualitative approaches. Educational Psychology, 11, 363-382. doi: 10.1080/0144341910110311

Rosenthal, R. (1994). Parametric measures of effect size. In H. Cooper \& L. V. Hedges (Eds.), The handbook of research synthesis (pp. 231-244). New York, NY: Russell Sage Foundation.

Russo, N., Kelly, M., \& Deacon, M. (1991). Gender and success-related attribution: Beyond individualistic conceptions of achievement. Sex Roles, 25, 331-350. doi: 10.1007/bf00289760

Sadler-Smith, E. (1996). Approaches to studying: Age, gender and academic performance. Educational Studies, 22, 367-379. doi: 10.1080/0305569960220306

Sadler-Smith, E., \& Tsang, F. (1998). A comparative study of approaches to studying in Hong Kong and the United Kingdom. British Journal of Educational Psychology, 68, 81-93. doi: 10.1111/j.2044-8279.1998.tb01276.x

Salamonson, Y., Weaver, R., Chang, S., Koch, J., Bhathal, R., Khoo, C., \& Wilson, I. (2013). Learning approaches as predictors of academic performance in first year health and science students. Nurse Education Today, 33, 729-733. doi: 10.1016/j.nedt.2013.01.013

Schertzer, C. B., \& Schertzer, S. M. (2004). Student satisfaction and retention: A conceptual 
model. Journal of Marketing for Higher Education, 14, 79-91. doi: 10.1300/j050v14n01_05

Severiens, S. E., \& Ten Dam, G. T. (1994). Gender differences in learning styles: A narrative review and quantitative meta-analysis. Higher Education, 27, 487-501. doi: 10.1007/bf01384906

Simpson, R. (2000). A voyage of discovery or a fast track to success: Men, women and the MBA. Journal of Management Development, 19, 764-782. doi: 10.1108/02621710010378219

Simpson, R., Sturges, J., Woods, A., \& Altman, Y. (2005). Gender, age, and the MBA: An analysis of extrinsic and intrinsic career benefits. Journal of Management Education, 29, 218-247. doi: $10.1177 / 1052562904263530$

Stone, C., \& O'Shea, S. E. (2013). Time, money, leisure and guilt-the gendered challenges of higher education for mature-age students. Australian Journal of Adult Learning, 53, 95116.

Sturges, J. (1999). What it means to succeed: Personal conceptions of career success held by male and female managers at different ages. British Journal of Management, 10, 239-252. doi: $10.1111 / 1467-8551.00130$

Tarabashkina, L., \& Lietz, P. (2011). The impact of values and learning approaches on student achievement: Gender and academic discipline influences. Issues in Educational Research, 21, 210-231.

Thacker, C., \& Novak, M. (1991). Student role supports for younger and older middle-aged women: Application of a life event model. Canadian Journal of Higher Education, 21, 1336.

Wilson, K. L., Smart, R. M., \& Watson, R. J. (1996). Gender differences in approaches to learning in first year psychology students. British Journal of Educational Psychology, 66, 59-71. doi: 10.1111/j.2044-8279.1996.tb01176.x

Zeegers, P. (2001). Approaches to learning in science: A longitudinal study. British Journal of Educational Psychology, 71, 115-132. doi: 10.1348/000709901158424 